\title{
Pharmacological Effects of withanolides
}

\author{
Zheng Wei ${ }^{1}$, Tingting $\mathrm{Li}^{1}$, Huilin $\mathrm{Su}^{2}$, Qiuhong Wang ${ }^{2 *}$ and Haixue Kuang ${ }^{1 *}$ \\ ${ }^{1}$ School of Pharmacy, Heilongjiang University of Chinese Medicine, China \\ ${ }^{2}$ School of Traditional Chinese Medicine, Guangdong Pharmaceutical University, China
}

*Corresponding author: Haixue Kuang, School of Pharmacy, Heilongjiang University of Chinese Medicine, 24 He ping Road, Xiang fang District, Harbin 150040, Heilongjiang, China

Qiuhong Wang, School of Traditional Chinese Medicine, Guangdong Pharmaceutical University, 280 Outer Ring Road, University Town, Guangzhou 510006, China

\begin{abstract}
Withanolides is a class of active compounds widely found in Solanaceae plants. In traditional applications, it has a long history and a wide range of functions. With the progress of drug structure and pharmacological research, more and more reports point to its excellent anticancer effect. Solanaceae is widely distributed, providing a large number of sources for the structure and pharmacological research of its natural products. At the same time, in the light of market demand, the circulation of such medicinal materials is enormous. Based on the pharmacological action of inhibiting NF- $\kappa$ B signaling pathway, withanolides has become a research hotspot in natural medicine. Perhaps combining traditional clinical practice will point out a new research direction to provide basic information for the development of new drugs for difficult cases.
\end{abstract}

Keywords: Withanolides; Withaferin A; Anti-inflammatory ; Anti-tumor; NF-кB

\section{Introduction}

Withania somnifera (L.) Dunal (Family, Solanaceae) commonly known as Ashwgandha or winter cherry is one of the top medicinal herbs used in Ayurveda-the holistic system of Indian medicine. The principle bioactive components, a group of secondary metabolites collectively called withanolides, are C-28 steroidal lactones [1]. Withaferin A, a steroidal lactone that was initially isolated from Withania somnifera (winter cherry) in 1965, and was the first member of the withanolides to be discovered (Figure 1). Withanolides is a series of small molecules widely found in
Solanaceae. The solanaceae plant is traditionally used to treat asthma, parasitic disease, constipation, edema, glaucoma, headache, hepatopathy, reducing swelling and inflammation, postpartum pain, skin diseases [2-4]. In the past decade, with the rapid development and application of various separation techniques and spectral analysis techniques, especially nuclear magnetic resonance spectroscopy, the research speed of the compounds in the solanaceae has been greatly accelerated, and its structural research has made great progress. Up to now, more than 900 kinds of withanolides have been separated from the whole world $[5,6]$.

Figure 1: The chemical structure of withaferin A. 
In recent years, many anti-inflammatory and cytotoxic effects of withanolides have been reported. Its pharmacological targets are more focused on the NF- $\mathrm{BB}$ and STAT3 signaling pathways. $\mathrm{NF}-\kappa \mathrm{B}$ regulates a great deal of physiological processes including cellular proliferation, development, differentiation, immunity, apoptosis, inflammation, and metabolism [7]. Abnormal STAT3 activity dysregulates growth and survival, promotes angiogenesis [8], migration and invasion of tumor cells, and induces tumorimmune tolerance. The activation and interaction between STAT3 and NF- $\kappa \mathrm{B}$ plays a pivotal role in control of the communication between cancer cells and inflammatory cells [8]. In addition, the anti-cancer activities of TNF- $\alpha$ are enhanced when combined with the withanolides [9]. Since the pathogenesis of cancer and psoriasis is similar in cell proliferation, inflammation, angiogenesis and related signaling pathways, psoriasis [10], arthritis, cancer and other autoimmune diseases will have a broad prospect for the experiment of withanolides.

\section{Plant origin}

Plants with withanolides are common in Datura wrightii, Jaborosa caulescens, Physalis hispida, P. longifolia, Vassobia breviflora, and Withania somnifera [11]. Withania somnifera, a multipurpose medicinal plant is a rich reservoir of pharmaceutically active triterpenoids that are steroidal lactones known as withanolides. W. somnifera [12] is widely distributed around the world and is mainly adapted to xeric and drier regions of tropical and subtropical domains, ranging from the Canary Islands, the Mediterranean region and Northern Africa to Southwest Asia. Long ago ,a Solanaceae plant, Flos Datura, together with Buddhism, was introduced from India to China and then widely distributed in the South and north of the country. Li Shizhen, a Chinese medical scientist in the Ming Dynasty, recorded in detail the efficacy and character of the Flos Datura in the Compendium of Materia Medica, and tested the medicine with his own body. Chinese scholar yang et al. found nine new anti-inflammatory withanolides from the leaves of Flos Daturae [13].

\section{Antitumor action}

Despite the development of a wide variety of anticancer drugs, the global incidence of various cancers, and the mortality thereof, is still on the rise. The number of cancer-related deaths is presumed to increase by two-fold in the next 50 years [14]. Different kinds of solanol lactone can show differences in anticancer activity and target, but anticancer is their common pharmacological characteristics [15]. NF- $\mathrm{KB}$ is a classic signal pathway for tumorigenesis $[7,16,17]$. A crosstalk between TP53 and NF- $\mathrm{B}$ pathways was involved in the regulation of mitochondrial fissionmediated cell survival [18]. Owing to recent advances in molecular biology, investigators have begun unraveling essential oncogenic pathways in carcinogenesis, potentiating an era of chemotherapy in which it is possible to theorize cancer specific targets. It has been repeatedly demonstrated that a variety of malignancies have aberrant or an elevated expression of intermediate filaments keratin (type I or II), nestin (type VI), and vimentin (type III) [19-24]. The type III intermediate filaments (IFs) are essential cytoskeletal elements of mechanosignal transduction and serve critical roles in tissue repair [25].

Although no potential antineoplastic agent has been identified to specifically target aberrant keratin or nestin levels in malignant cells, withanolides have shown promise as a potent type III intermediate filament inhibitor.

Withaferin A has been shown to potently inhibit a variety of proteins, with the most notable target being vimentin and other type III intermediate filaments [26-30] (Figure 2). In addition to its affinity for intermediate filaments, withaferin $\mathrm{A}$ has been shown repeatedly to inhibit angiogenesis by inhibiting the NF$\kappa \mathrm{B}$ signaling pathway [29-33]. Withaferin A can also suppress estrogen receptor- $\alpha$ expression in human breast cancer cells [34], another report is by inhibiting the STAT3 signaling pathway [35]; Meanwhile, withaferin A promotes bone formation by inhibiting $\mathrm{NF}-\kappa \mathrm{B}$ pathway in the treatment of ovariectomized osteoporosis models [36], implied the potential role of withaferin A and estrogen.

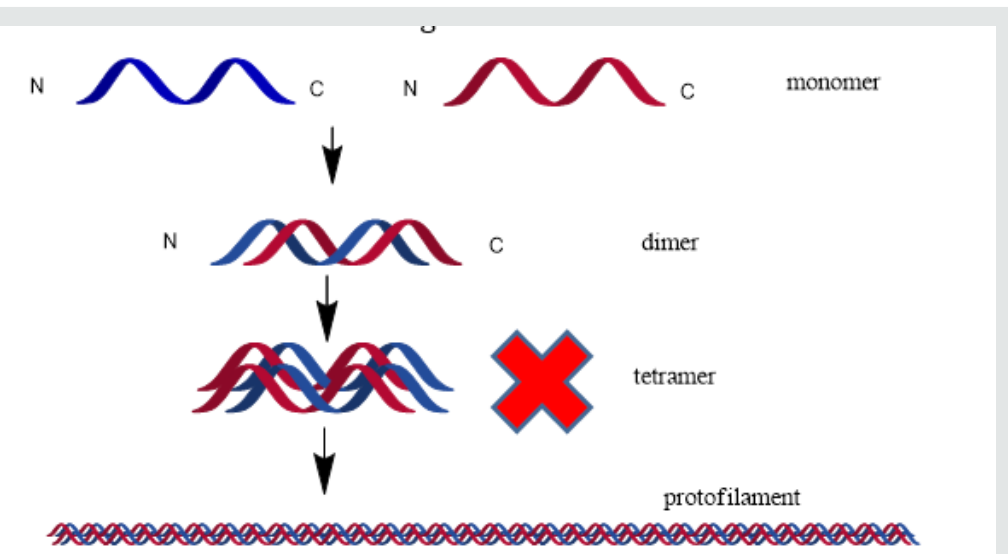

Inhibits the formation of all type 3 intermediate filaments.

Figure 2: Antineoplastic mechanisms of intermediate filament-disrupting withaferin A. 
Withaferin A also elicits antineoplastic activity in a considerable variety of cancer cell lines by directly inhibiting neoplastic growth, including carcinomas of the head and neck, ovaries, and thyroid, as well as glioblastoma multiforme and melanoma [33,37-40]. Owingto its notable anti-angiogenic activity, withaferin $\mathrm{A}$ has demonstrated significant synergistic effects with the multikinase inhibitor sorafenib [41], suggesting that withaferin A may be a viable supplement for renal cell carcinomas, and other malignancies notably affected by the inhibition of neoplastic angiogenesis. It should also be noted that withaferin A, withalongolide A (a 19-hydroxy derivative of withaferin A), and several other closely related congeners may influence signaling regulated by the PI3K/ AKT/mTOR pathway. These congeners suppress RET and Akt phosphorylation and protein expression, as well as inhibit mTOR activity, the translational activity of 4EBP1, and protein synthesis mediated by p70S6 kinase activation in neoplastic cells [patientderived medullary thyroid carcinoma cells, as well as human and murine glioblastoma cells in vitro $[42,43]$.

These data indicate a potential synergistic relationship between withanolides and mTOR inhibitors currently used in the clinical setting and warrant further preclinical investigation. Physalin A, a bioactive withanolide derived from Physalis alkekengi, used in traditional Chinese medicine, exerts anti-tumor activity in nonsmall cell lung cancer cell lines by suppressing JAK/STAT3 signaling [44].

\section{Anti-inflammatory effect}

Inflammation, it was Rudolf Virchow, a German physician in nineteenth century who suggested a link between inflammation and cancer, cardiovascular diseases, diabetes, pulmonary diseases, neurological diseases, skin diseases and other chronic diseases. It is reported that withaferin A can directly destroy the two-dimer structure of NF- $\kappa B$ [45], inhibits the activity of DNA-binding, inhibits the NEMO/IKK $\beta$ association complex formation [46], or by directly targeting the catalytic kinase activity of IKK $\beta$ [47]. It suggests that Withania somnifera leaf water extract inhibits microglial activation and migration and may prove to be a potential therapeutic candidate for the suppression of neuroinflammation in the treatment of neurodegenerative diseases [48]. Kallol Dutta, et al. tested an extract of W. somnifera that had the potency to reduce in a dosedependent fashion the activity of NF- $\mathrm{B}$ P 65 -luciferase reporter in the microglial cultured BV2 cells [49]. Withania somnifera water extract reduces LPS-induced NF- $\kappa \mathrm{B}$ activity in DI TNC1 astrocytes [50]. Withaferin A may be an eligible candidate for the treatment of neuroinflammatory and stress conditions characterized by an important astrocytic input [51]. Perhaps inhibiting mitochondrial oxidative stress is the initial role of withanolides [52].

\section{Discussion and Future Direction}

In addition to Withaferin A, many of the withanolides are isolated from Solanaceae plants $[11,53,54]$. Through the understanding of the anti-tumor and anti-inflammatory effects of Withaferin A, we can find the pharmacological characteristics of withanolides. First, the anti-cancer and anti-inflammatory effects are more through the NF- $\kappa$ B pathway; secondly, the combination of anti-proliferation and pro-apoptosis; finally, the bi-directional regulation of cytotoxicity and cell protection (Figure 3).

Structure determines efficacy. Based on their pharmacological generality, withanolides may have multiple functions, such as anti-inflammatory, anti- proliferation, promoting apoptosis, and inhibiting angiogenesis. Psoriasis, a chronic inflammatory dermatosis, which contains all the characteristics of the autoimmune disease [55], and it needs a highly effective and inexpensive drug containing all the above functions. The two signaling pathways of NF- $\kappa \mathrm{B}$ and STAT3 have been proved to play an important role in the pathological process of psoriasis [56-58], and there may be interactions between them $[59,60]$. In the clinical application of traditional Chinese medicine, the extract of Flos Daturae has achieved exact effect in the treatment of psoriasis [61-63] (Figure 4). It is preliminarily believed that the substance base of this effect is withanolides. The Relationship of its structure-activity still needs further study.

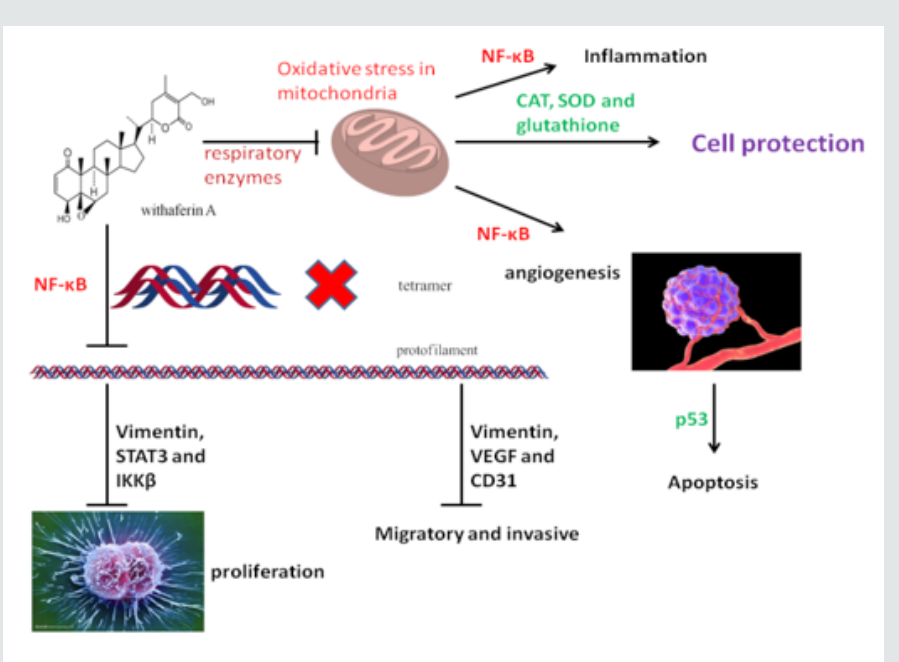

Figure 3: A schematic diagram of the pharmacological action of withaferin A. 

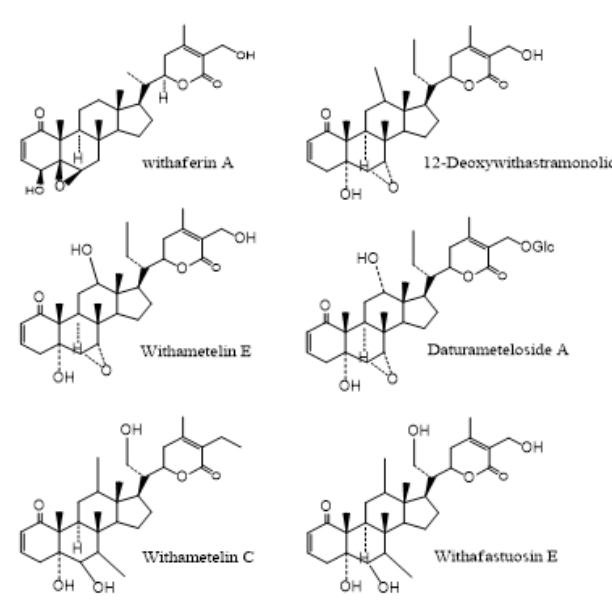

Figure 4: Withaferin A and part of withanolides separated from the Flos Daturae.

\section{References}

1. Misra L, Lal P, Sangwan RS, Sangwan NS, Uniyal GC (2005) Unusually sulfated and oxygenated steroids from Withania somnifera. Phytochemistry 66(23): 2702-2707.

2. Anjalam A, Kalpana S, Vijai D, Premalatha S (2016) Documentation of medicinal plants used by malayali tribes in Kolli Hills. Int J Adv Res Biol Sci 3(3): 101-107.

3. Sharmila S, Kalaichelvi K, Rajeswari M, Anjanadevi N (2014) Studies on the Folklore Medicinal Uses of Some Indigenous Plants Among The Tribes of Thiashola, Manjoor, Nilgiris South Division, Western Ghats. International Journal of Plant, Animal and Environmental Sciences 4(3): 14-22.

4. Njoroge GN, Bussmann RW (2009) Ethnotherapeutic management of sexually transmitted diseases (STDs) and reproductive health conditions in Central Province of Kenya. Indian Journal of Traditional Knowledge 8(2): 255-261.

5. Cao CM, Zhang H, Gallagher RJ, Day VW, Kindscher K, et al. (2014) Withanolides from Physalis hispida. J Nat Prod 77(3): 631-639.

6. Zhang H, Samadi AK, Cohen MS, Timmermann BN (2012) Antiproliferative withanolides from the Solanaceae: a structure-activity study. Pure Appl Chem 84(6): 1353-1367.

7. Karin M (2006) Nuclear factor-kappa B in cancer development and progression. Nature 441(7092): 431-436.

8. Lee TL, Yeh J, Friedman J, Yan B, Yang X, et al. (2008) A signal network involving coactivated NF-kappaB and STAT3 and altered p53 modulates BAX/BCL-XL expression and promotes cell survival of head and neck squamous cell carcinomas. Int J Cancer 122(9): 1987-1998.

9. Lu L, Shi W, Deshmukh RR, Long J, Cheng X, et al. (2014) Tumor necrosis factor- $\alpha$ sensitizes breast cancer cells to natural products with proteasome-inhibitory activity leading to apoptosis. PLoS One 9(11): e113783.

10. Kuang H, Yao F, Wang Q Yang B, Xiao H (2008) Studies on pharmacological actions of the effective parts for psoriasis in Flos Daturae (I). Chin J Exp Trad Med Formulae.

11. Zhang H, Cao CM, Gallagher RJ, Timmermann BN (2014) Antiproliferative withanolides from several solanaceous species. Nat Prod Res 28(22): 1941-1951.

12. Mirjalili MH, Moyano E, Bonfill M, Cusido RM, Palazón J (2009) Steroidal lactones from Withania somnifera, an ancient plant for novel medicine.
Molecules 14(7): 2373-2393.

13. Yang BY, Guo R, Li T, Wu JJ, Zhang J, et al. (2014) New anti-inflammatory withanolides from the leaves of Datura metel L. Steroids 87: 26-34.

14. Mann JR, Backlund MG, DuBois RN (2005) Mechanisms of disease: Inflammatory mediators and cancer prevention. Nat Clin Pract Oncol 2(4): 202-210.

15. Vaishnavi K, Saxena N, Shah N, Singh R, Manjunath K, et al. (2012) Differential activities of the two closely related withanolides, Withaferin $A$ and Withanone: bioinformatics and experimental evidences. PLoS One $7(9)$ : e44419.

16. Lu T, Sathe SS, Swiatkowski SM, Hampole CV, Stark GR (2004) Secretion of cytokines and growth factors as a general cause of constitutive NFkappa B activation in cancer. Oncogene 23(12): 2138-21345.

17. Wu D, Wu P, Zhao L, Huang L, Zhang Z, et al. (2015) NF- $\kappa B$ Expression and Outcomes in Solid Tumors: A Systematic Review and Meta-Analysis. Medicine (Baltimore) 94(40): e1687.

18. Huang Q, Zhan L, Cao H, Li J, Lyu Y, et al. (2016) Increased mitochondrial fission promotes autophagy and hepatocellular carcinoma cell survival through the ROS-modulated coordinated regulation of the NFKB and TP53 pathways. Autophagy 12(6): 999-1014.

19. Karantza V (2011) Keratins in health and cancer: more than mere epithelial cell markers. Oncogene 30(2): 127-138.

20. Bauman PA, Dalton WS, Anderson JM, Cress AE (1994) Expression of cytokeratin confers multiple drug resistance. Proc Natl Acad Sci U S A 91(12): 5311-5314.

21. Liu F, Fan D, Qi J, Zhu H, Zhou Y, et al. (2008) Co-expression of cytokeratin 8 and breast cancer resistant protein indicates a multifactorial drugresistant phenotype in human breast cancer cell line. Life Sci 83(13-14): 496-501.

22. Teranishi N, Naito Z, Ishiwata T, Tanaka N, Furukawa K, et al. (2007) Identification of neovasculature using nestin in colorectal cancer. Int J Oncol 30(3): 593-603.

23. Krupkova 0, Loja T, Zambo I, Veselska R (2010) Nestin expression in human tumors and tumor cell lines. Neoplasma 57(4): 291-298.

24. Satelli A, Li S (2011) Vimentin in cancer and its potential as a molecular target for cancer therapy. Cell Mol Life Sci 68(18): 3033-3046.

25. Herrmann H, Bär H, Kreplak L, Strelkov SV, Aebi U (2007) Intermediate filaments: from cell architecture to nano mechanics. Nat Rev Mol Cell Biol 8(7): 562-573. 
26. Vanden BW, Sabbe L, Kaileh M, Haegeman G, Heyninck K (2012) Molecular insight in the multifunctional activities of Withaferin A. Biochem Pharmacol 84(10): 1282-1291.

27. Bargagna-Mohan P, Hamza A, Kim YE, Khuan Abby Ho Y, Mor-Vaknin N et al. (2007) The tumor inhibitor and antiangiogenic agent withaferin A targets the intermediate filament protein vimentin. Chem Biol 14(6): 623-634.

28. Bargagna-Mohan P, Paranthan RR, Hamza A, Dimova N, Trucchi B, et al. (2010) Withaferin A targets intermediate filaments glial fibrillary acidic protein and vimentin in a model of retinal gliosis. J Biol Chem 285(10): 7657-7669.

29. Bargagna-Mohan P, Paranthan RR, Hamza A, Zhan CG, Lee DM, et al. (2012) Corneal antifibrotic switch identified in genetic and pharmacological deficiency of vimentin. J Biol Chem 287(2): 989-1006.

30. Grin B, Mahammad S, Wedig T, Cleland MM, Tsai L, et al. (2012) Withaferin a alters intermediate filament organization, cell shape and behavior. PLoS One 7(6): e39065.

31. Yokota Y, Bargagna-Mohan P, Ravindranath PP, Kim KB, Mohan R (2006) Development of withaferin A analogs as probes of angiogenesis. Bioorg Med Chem Lett 16(10): 2603-2607.

32. Mohan R, Hammers HJ, Bargagna-Mohan P, Zhan XH, Herbstritt CJ, et al. (2004) Withaferin A is a potent inhibitor of angiogenesis. Angiogenesis $7(2): 115-122$

33. Bargagna-Mohan P, Ravindranath PP, Mohan R (2006) Small molecule anti-angiogenic probes of the ubiquitin proteasome pathway: potential application to choroidal neovascularization. Invest Ophthalmol Vis Sci 47(9): 4138-4145.

34. Hahm ER, Lee J, Huang Y, Singh SV (2011) Withaferin a suppresses estrogen receptor- $\alpha$ expression in human breast cancer cells. Mol Carcinog 50(8): 614-624.

35. Lee J, Hahm ER, Singh SV (2010) Withaferin A inhibits activation of signal transducer and activator of transcription 3 in human breast cancer cells. Carcinogenesis 31(11): 1991-198.

36. Khedgikar V, Kushwaha P, Gautam J, Verma A, Changkija B, et al. (2013) Withaferin A: a proteasomal inhibitor promotes healing after injury and exerts anabolic effect on osteoporotic bone. Cell Death Dis 4: e778.

37. Samadi AK, Tong X, Mukerji R, Zhang H, Timmermann BN, Cohen MS (2010) Withaferin A, a cytotoxic steroid from Vassobia breviflora, induces apoptosis in human head and neck squamous cell carcinoma. J Nat Prod 73(9): 1476-1481.

38. Zhang X, Mukerji R, Samadi AK, Cohen MS (2011) Down-regulation of estrogen receptor-alpha and rearranged during transfection tyrosine kinase is associated with withaferin a-induced apoptosis in MCF-7 breast cancer cells. BMC Complement Altern Med 11: 84.

39. Zhang X, Samadi AK, Roby KF, Timmermann B, Cohen MS (2012) Inhibition of cell growth and induction of apoptosis in ovarian carcinoma cell lines CaOV3 and SKOV3 by natural withanolide Withaferin A. Gynecol Oncol 124(3): 606-612.

40. Samadi AK, Cohen SM, Mukerji R (2012) Natural withanolide withaferin A induces apoptosis in uveal melanoma cells by suppression of Akt and c-MET activation. Tumour Biol 33(4): 1179-1189.

41. Cohen SM, Mukerji R, Timmermann BN, Samadi AK, Cohen MS (2012) A novel combination of withaferin A and sorafenib shows synergistic efficacy against both papillary and anaplastic thyroid cancers. Am J Surg 204(6): 895-900.

42. Grogan PT, Sleder KD, Samadi AK, Zhang H, Timmermann BN, et al. (2013) Cytotoxicity of withaferin A in glioblastomas involves induction of an oxidative stress-mediated heat shock response while altering Akt/ mTOR and MAPK signaling pathways. Invest New Drugs 31(3): 545-557.
43. Samadi AK, Bazzill J, Zhang X (2012) Novel withanolides target medullary thyroid cancer through inhibition of both RET phosphorylation and the mammalian target of rapamycin pathway. Surgery 152(6): 1238-1247.

44. Zhu F, Dai C, Fu Y, Loo JF, Xia D, et al. (2016) Physalin A exerts anti-tumor activity in non-small cell lung cancer cell lines by suppressing JAK/ STAT3 signaling. Oncotarget 7(8): 9462-9676.

45. Ashkenazi S, Plotnikov A, Bahat A, Ben Zeev E, Warszawski S, et al. (2016) A Novel Allosteric Mechanism of NF- $\mathrm{KB}$ Dimerization and DNA Binding Targeted by an Anti-Inflammatory Drug. Mol Cell Biol 36(8): 1237-1247.

46. Grover A, Shandilya A, Punetha A, Bisaria VS, Sundar D (2010) Inhibition of the NEMO/IKK $\beta$ association complex formation, a novel mechanism associated with the NF- $\kappa \mathrm{B}$ activation suppression by Withania somnifera's key metabolite withaferin A. BMC Genomics 11 Suppl 4: S25.

47. Heyninck K, Lahtela Kakkonen M, Van Der Veken P, Haegeman G, Vanden BW (2014) Withaferin A inhibits NF-kappa B activation by targeting cysteine 179 in IKK $\beta$. Biochem Pharmacol 91(4): 501-509.

48. Gupta M, Kaur G (2016) Aqueous extract from the Withania somnifera leaves as a potential anti-neuroinflammatory agent: a mechanistic study. J Neuroinflammation 13(1): 193

49. Dutta K, Patel P, Rahimian R, Phaneuf D, Julien JP (2017) Withania somnifera Reverses Transactive Response DNA Binding Protein 43 Proteinopathy in a Mouse Model of Amyotrophic Lateral Sclerosis/ Frontotemporal Lobar Degeneration. Neurotherapeutics 14(2): 447462 .

50. Ajit D, Simonyi A, Li R (2017) Phytochemicals and botanical extracts regulate NF- $\mathrm{KB}$ and Nrf2/ARE reporter activities in DI TNC1 astrocytes. Neurochem Int 97: 49-56.

51. Martorana F, Guidotti G, Brambilla L, Rossi D (2015) Withaferin A Inhibits Nuclear Factor- $\kappa B$-Dependent Pro-Inflammatory and Stress Response Pathways in the Astrocytes. Neural Plast 2015: 381964.

52. Vedi M, Rasool M, Sabina EP (2014) Amelioration of bromobenzene hepatotoxicity by Withania somnifera pretreatment: Role of mitochondrial oxidative stress. Toxicol Rep 1: 629-638.

53. Zhang H, Bazzill J, Gallagher RJ (2013) Antiproliferative withanolides from Datura wrightii. J Nat Prod 76(3): 445-449.

54. Zhang H, Motiwala H, Samadi A (2012) Minor withanolides of Physalis longifolia: structure and cytotoxicity. Chem Pharm Bull (Tokyo) 60(10): 1234-1239.

55. Woo YR, Cho DH, Park HJ (2017) Molecular Mechanisms and Management of a Cutaneous Inflammatory Disorder: Psoriasis. Int J Mol Sci 18(12).

56. Sano S, Chan KS, Carbajal S, et al. Stat3 (2013) links activated keratinocytes and immunocytes required for development of psoriasis in a novel transgenic mouse model. Nat Med 11(1): 43-49.

57. Goldminz AM, Au SC, Kim N, Gottlieb AB, Lizzul PF (2013) NF- $\kappa B$ : an essential transcription factor in psoriasis. J Dermatol Sci 69(2): 89-94.

58. Moorchung N, Kulaar JS, Chatterjee M, Vasudevan B, Tripathi T, et al. (2014) Role of NF- $\kappa B$ in the pathogenesis of psoriasis elucidated by its staining in skin biopsy specimens. Int J Dermatol 53(5): 570-574.

59. Hillmer EJ, Zhang H, Li HS, Watowich SS (2016) STAT3 signaling in immunity. Cytokine Growth Factor Rev 31: 1-15.

60. Squarize CH, Castilho RM, Sriuranpong V, Pinto DS, Gutkind JS (2006) Molecular cross-talk between the NFkappa B and STAT3 signaling pathways in head and neck squamous cell carcinoma. Neoplasia 8(9): 733-746.

61. Yang BY, Xia YG, Wang QH, Dou DQ, Kuang HX (2010) Baimantuoluosides $D-G$, four new withanolide glucosides from the flower of Datura metel L. Arch Pharm Res 33(8): 1143-1148. 
62. Wang Y (1985) the report on Traditional Chinese medicine yangjinhua (Datura metel) is given priority to treat 242 patients with psoriasis.

63. Wang QH, Xiao HB, Yang BY, Yao FY, Kuang HX (2008) Studies on Pharmacological Actions of the Effective Parts for Psoriasis in Flos
Daturae (I) The Anti-inflammatory, Anti-titillation and Anti-anaphylaxis Actions of Flos daturae. Chinese Journal of Experimental Traditional Medical Formulae.

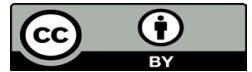

This work is licensed under Creative Commons Attribution 4.0 License

To Submit Your Article Click Here:

Submit Article

DOI: 10.32474/OAJCAM.2019.01.000125

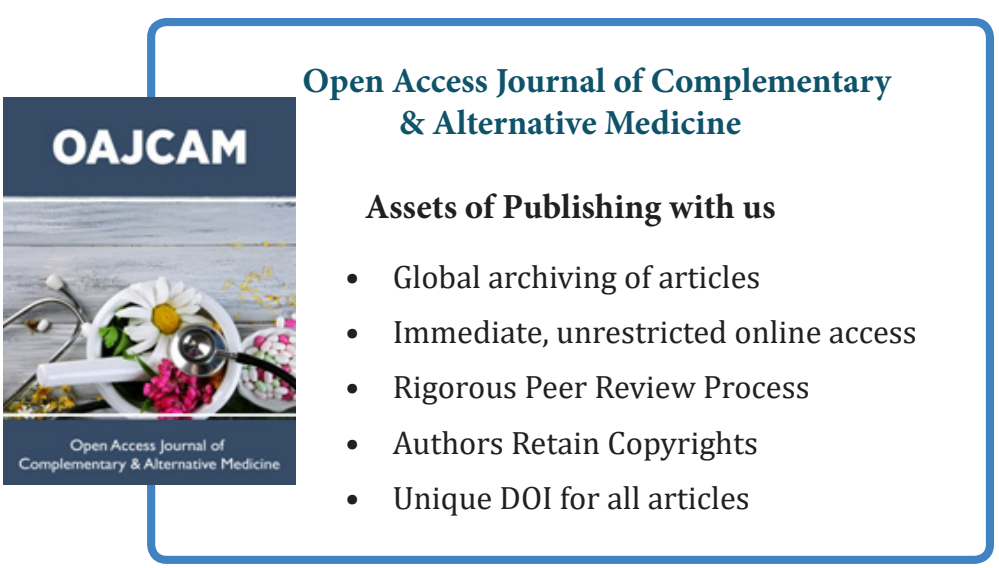

